\title{
Amor em tempos de aplicativo: entrevista com a antropóloga Larissa Pelúcio
}

\author{
Entrevistador MÁRIO FELLIPE FERNANDES VIEIRA VASCONCELOS \\ Universidade Federal do Ceará, Fortaleza, Ceará, Brasil \\ fernandesvv10@gmail.com
}

DOI 10.11606/issn.2316-9133.v29i2pe175150

Era tempo de isolamento social. O vírus da COVID-19 havia aportado no mundo, ilhando-nos em nossas casas e alterando de modo irreversível nossas vidas e relações sociais. Máscara, álcool em gel e distanciamento compunham o combo que vestia nossos corpos, imprimindo neles novas posturas e autorizando sua circulação no espaço urbano. A comunicação digitalmente mediada tinha se transformado na forma de interação social dominante: home office, ensino remoto e lives não só exigiam adaptações em nossa rotina, mas sinalizavam mudanças sensíveis na esfera social e subjetiva. Essa entrevista foi realizada nesse contexto. A pandemia e a ambiência produzida pelo isolamento social foram realidades que acionaram a produção desse material reflexivo que versa sobre as transformações emocionais e afetivas do tempo presente.

Como efeito de um contexto marcado pela presença massiva das tecnologias digitais em nossa vida cotidiana, temos vivenciado um processo de mudança nas formas de nos relacionarmos social e subjetivamente. Essas transformações estão relacionadas às inflexões no modelo de produção capitalista, atualmente com foco na articulação entre mercado e capital financeiro. A emergência de uma sociedade neoliberal marcou o fim de uma era monopolizada pelo capitalismo industrial de tipo disciplinar, cujo projeto era o de produzir subjetividades adestradas e ajustadas aos moldes das instituições sociais. O neoliberalismo inaugurou uma nova razão de mundo que tem modificado não somente a configuração das formas de controle social, hoje pautadas na flexibilização e em diversas formas de precarização, mas também a subjetividade dos indivíduos, que se torna de tipo empreendedora, resultante da incorporação de um modelo de gestão estratégica.

Contrariando as formulações de Zigmunt Bauman sobre a liquidez dos laços humanos, produzida por uma sociedade de consumidores conectados, Larissa Pelúcio, na esteira de Eva Illouz, afirma que as relações digitais são profundamente emocionais. Nas redes, amamos, destilamos ódio, criamos e desfazemos relações sociais, performamos vidas felizes, decidimos o futuro eleitoral de um país. Contudo, se também produzimos em série e 
a um ritmo acelerado várias expressões de emoção, ainda, segunda a antropóloga, passamos a temer qualquer forma de engajamento social e emocional, bloqueando e cancelando aqueles e aquelas que contrariam o nosso modo de perceber e vivenciar a realidade. Imersos em um mercado, regido pela desigualdade de oportunidades, nossos temores e incertezas acerca de nossas vidas pessoais e coletivas têm alimentando o processo de acumulação competitiva desse novo capitalismo.

A entrevista consiste, nesse sentido, em um exercício de compreensão antropológica da paisagem emocional das relações heterossexuais do tempo presente, com ênfase nas transformações que os aplicativos trouxeram nos padrões de interação social, nas formas de produção de si e nas relações entre os gêneros, o que demonstra que o acontece nos aplicativos tem tido ressonância no mundo offline ou é subproduto desse.

Com respostas dotadas de profunda densidade, Larissa Pelúcio costura os fios que unem o modelo do amor romântico do final do século XIX até meados do século XX aos do amor da era do neoliberalismo tecnológico. Considerando que estamos vivendo em tempos de isolamento social em função da pandemia do novo Corona vírus, a autora lança para nós uma questão bastante complexa para compreendermos o processo de desigualdade e assimetrias sociais, étnico-raciais e de gênero que, em um contexto de pandemia, tornam-se acentuados. Desse modo, ilhados em diferentes embarcações que revelam a desigual distribuição dos meios de sobrevivência, a autora nos incita a pensar sobre o nosso lugar de privilégio que torna peculiar o nosso isolamento como sujeitos brancos e de classe média: "quem são os sujeitos que podem estar confinados em casa, dispor de dados móveis, celular, tempo e local para, por exemplo, para fazer um sexting?".

$* * *$

MÁRIO FELLIPE: Larissa eu queria que, inicialmente, você falasse um pouco do seu último livro lançado pela Annablume/FAPESP, (cf. PELUCIO 2019). Como começou essa pesquisa e quais os principais desafios em realizá-la?

LARISSA PELÚCIO: Primeiro dizer que esse livro é resultado de um Auxílio Regular de Pesquisa financiada pela Fundação de Amparo à Pesquisa do Estado de São Paulo, a FAPESP. Bem como que a publicação da pesquisa em formato de livro contou com financiamento da mesma Fundação.

Bem, vou te responder dizendo uma coisa que eu escrevi em um artigo que saiu este ano na revista Interfaces Científicas (cf. PELUCIO 2020) ${ }^{1}$. Quando comecei a pensar no impacto dos usos dos aplicativos sobre a forma que nos relacionarmos amorosa e sexualmente, eu estava pensando mais em masculinidades do que em relacionamentos. De uma maneira mais divertida, eu diria que eu estava à procura de homens e não de amor. Me interessava compreender como eles estavam construindo, por meio das comunicações

\footnotetext{
${ }^{1}$ A entrevista foi realizada em abril de 2020.
} 
digitais, seus afetos, lidando com seus medos, negociando seus interesses e, mesmo, paixões "em um mundo questionado pelo feminismo, pelo movimento gay, pelos estudos de gênero e pela teoria queer?” (FRANCO 2015: p. 45). Me interessava a intimidade dos homens heterossexuais desafiados em suas vidas privadas pelas inflexões feministas pelas quais o país passou na última década.

Então, eu estava pensando também nos impactos dos feminismos para a vida íntima, pois quando eu olhava os dados de pesquisa, por exemplo, uma pesquisa conduzida pela Fundação Perseu Abramo ${ }^{2}$, ali aparecia que no espaço de 09 anos (entre 2001 a 2010) o feminismo cresceu $10 \%$ entre as entrevistadas. Quando a gente olha para as porcentagens o aumento pode não parecer tão significativo. Veja, em 2001, 21\% das mulheres se reconheciam feministas, em 2010, tínhamos 31\%. Mas a verdade é que esses números estavam aparecendo na forma das mulheres se posicionarem em diferentes ambientes: nas periferias, o aparecimento do feminismo interseccional; os coletivos feministas nas universidades; na maior escolarização entre mulheres do que entre homens (vale a pena ver os dados do IBGE sobre isso). Logo nós iríamos ver as Marchas das Vadias sendo organizadas em muitas cidades Brasil a fora. A Marcha das Margaridas, organizada pelas mulheres dos meios rurais; as Marchas das Mulheres Negras e também indígenas.

Dava para sentir as mudanças no perfil sócio demográfico das mulheres brasileiras. A pesquisa "Estatísticas de Gênero - Uma análise dos resultados do Censo Demográfico 2010" revelou que a escolaridade das mulheres aumentou em relação à dos homens. No ensino médio é $9,8 \%$ maior que a de homens. No nível superior, em 2010, elas representavam $57,1 \%$ do total de estudantes entre 18 e 24 anos. Mais escolarizadas, com melhor empregabilidade do que muitos homens, muitas mulheres têm adiado a maternidade e priorizado a vida profissional.

Apesar dessas mudanças significativas, que atingiu até mesmo o mercado editorial, que passou a publicar muita coisa sobre feminismos, o que eu acompanhava nos corredores da universidade, em papos com amigas, ouvindo conversa alheia no metrô, prestando atenção em postagens das redes sociais digitais, lendo os comentários feitos por leitores em grandes portais de notícias, era que, apesar disso tudo, ainda havia uma grande dominação emocional (ILLOUZ 2012) dos homens sobre as mulheres. Mas eu queria mesmo saber como os homens estavam respondendo a esse novo cenário no campo das relações íntimas. Como eu disse há pouco, esse interesse vinha provocado por uma espécie de roteiro de queixas vindas de amigas, alunas, de conversas flagradas em filas de supermercado, de matérias de revista femininas onde eu via mulheres entre 25 e 50 anos dizendo das dificuldades em terem relações heterossexuais respeitosas, simétricas, prazerosas, melhor pactuadas e menos efêmeras. Então, eu pensei que seria importante ouvir os homens.

Para conversar com homens, que dividi em 3 faixas etárias, eu abri perfis pessoais em aplicativos móveis para encontros sexuais/amorosos. Me anunciei como pesquisadora:

\footnotetext{
2 Trata-se da pesquisa de opinião "Mulheres brasileiras e gênero nos espaços público e privado", desenvolvida pela Fundação Perseu Abramo em agosto de 2010.
} 
“Antropóloga pesquisando masculinidades, tecnologias e afetos. Quer colaborar?”. Esse era meu texto de apresentação. Em dois anos de imersão online, tive mais de 300 crushs e matchs, e com alguns deles consegui fazer entrevistas em profundidade, com outros mantive conversas informais em torno dos temas que balizavam a pesquisa, outros ainda colaboraram pontualmente e nunca mais nos falamos e teve mesmo os que colaboraram mesmo se recusando em fazer parte da pesquisa. É interessante isso, o quanto a recusa, as justificativas para não participar ou a negociação para se integrar ou não à pesquisa geraram dados muito relevantes para que eu pudesse pensar em masculinidades e em metodologia.

Nessas interlocuções foi possível perceber como eles estavam negociando afetos e lidando com as normas hegemônicas de masculinidades em interações com mulheres que, mais do que eles, vinham experimentando um cenário de profundas mudanças sociais e culturais, o que as fez mais exigentes em relação a possíveis companheiros sexuais/amorosos. Pelo menos em teoria. O que constatei, após quase três anos de pesquisa, é que sim, eu tinha alguma razão nessa minha hipótese, mas também conclui que os relacionamentos heterossexuais ensaiados por aplicativos para fins de paquera não são um jogo de soma zero, as mulheres ainda se machucam mais com os "ghostings" (desaparecimentos súbitos) ou embarcam mais facilmente em conversas que parecem promissoras, nas quais o cara se declara e tudo mais, mas que pouco depois também some. Não é incomum que as mulheres se perguntem o porquê e pensem que a culpa é delas. Não que os homens não passem por isso, mas, o que percebi em minha pesquisa, é que quando esse tipo de coisa acontece com homens (o que é mais raro, pois veja, se uma mulher chega já com muitos elogios e com propostas de encontros, tende a ser percebida como "desesperada", "louca", "grudenta"), eles tendem a transferir o insucesso do "crush" para a mulher.

Desafiados por esse cenário descrito há pouco, muitos de meus interlocutores não hesitaram em reconhecer que essas mudanças estruturais, pessoais e subjetivas os desestabilizavam, provocando dúvidas e, no limite, recusas a comportamentos femininos que expressassem essas reconfigurações na ordem binária e heteronormativa dos gêneros.

Os homens com os quais mantive contato estavam se dando conta, não sem resistência da parte de muitos deles, de que precisam viver, trabalhar, se divertir e amar em uma sociedade na qual práticas e teorias feministas voltaram a ter expressão. Deparam-se com elas em seus perfis pessoais no Facebook, a partir de comentários, nem sempre bemvindos, feitos por amigas e/ou colegas de trabalho; nos grupos de famílias ou de colegas no WhatsApp; em matérias e reportagens veiculadas nas mídias massivas ou simplesmente flertando em um aplicativo.

MÁRIO FELLIPE: Em se tratando de amor em tempos de apps, o que você acha que mudou na paisagem emocional do período de realização da pesquisa para o contexto atual marcado pelo isolamento social? 
LARISSA PELÚCIO: Então Fellipe, como socióloga e antropóloga, eu acho arriscado falar em mudança na paisagem emocional agora que eu estou fora do campo de pesquisa desde 2017 e que muita coisa aconteceu no Brasil e nos aplicativos. A forma como as pessoas usam o app tem a ver com o que acontece no plano macro. Para você ter uma ideia, quando eu saí de campo, as polarizações políticas estavam começando a tensionar o ambiente dos apps. Não demorou muito e os perfis de usuários começaram a ser compostos por hashtags do tipo "foi golpe", "não foi golpe"3... Um antigo colaborador me contava, recentemente, que até outro dia nos aplicativos as conversas começavam com "votou em quem?". Nesse momento, acho que deve começar "quarentena" ou "cloroquina"? Falando sério, independente das polarizações, penso que, em alguma medida, estamos todos impactados por uma transformação tão aguda no cotidiano das cidades e das casas que ainda estamos elaborando como vamos lidar com nosso desejo.

Um grupo de pesquisadoras e pesquisadores, como Paula Sandrine Machado (Universidade Federal do Rio Grande do Sul) e Marco Aurélio Prado (Universidade Federal de Minas Gerais), está desenvolvendo uma pesquisa sobre sexualidade e desejo durante esse momento do isolamento social ${ }^{4}$, iniciando com o estabelecimento do isolamento social, procurando entender as estretégias preventivas que as pessoas estão buscando para ter contato físico, sexual com outras. A pesquisa dialoga com outro momento de pandemia, aos anos de 1980 e 1990 quando a pandemia da aids impactou grandemente a nossa forma de transar, desejar, buscar parceiras e parceiros. Não impactou só homens gays, talvez sim, de início, mas, em poucos anos, a camisinha entrou nas relações e, junto com ela, todo um novo vocabulário técnico: sexo seguro, redução de danos, testagem, hiv... E, neste momento, o que se tem feito? Admitamos que as pessoas continuam querendo encontrar alguém legal para compartilhar esse momento tão desafiador e cheio de incertezas. Mas há o medo, assim como a culpa de estar se colocando em risco e a outros também. Veja, estamos reavivando as categorias "risco" e "cuidado", termos que vem do campo da saúde, caros também às ciências sociais e, no caso do "cuidado", ao movimento feminista. Veja como o gênero aparece como um importante marcador quando se tem o aumento de violências doméstica, nesse momento, e que as redes sociais digitais podem atuar como um meio possível de denúncia, de pedido de ajuda.

Acredito que hoje, assim como no momento da minha pesquisa, nós precisemos levar em conta também as marcas geracionais, porque os usos das mídias mudam bastante conforme a idade. Temos que pensar também nas questões de classe. Quem conseguiu fazer o isolamento de verdade? Quem pode fazê-lo? Quem pode fazê-lo com internet, dados móveis, celular, tempo e local para, por exemplo, fazer um sexting?

\footnotetext{
${ }^{3}$ Pelúcio de refere à contenda política que polarizou opiniões quando do Impeachment de Dilma Roussef, processo que se iniciou em 02/12/2015 e teve fim em 31/08/2016, quando Michel Temer assumiu. Muitas pessoas entenderam que todo o processo configurou um golpe parlamentar, daí as hashtags.

${ }^{4}$ Iniciado oficialmente em 16 de março e teve duração variada de acordo com cada município do país, mas que perdurou de forma mais restritiva até fim de junho de 2020
} 
Voltando a falar de sexo, penso que talvez, dada a impossibilidade prudente do não encontro presencial, as pessoas possam ter adotado o Zoom como uma plataforma interessante. Basta a gente pegar os dados que indicam que o Zoom cresceu 19 vezes desde janeiro de 2020. Este crescimento tem relação com o tele-trabalho, mas, desde os primórdios da internet comercial, pessoas erotizaram o ambiente de trabalho, fazendo uso, por exemplo, dos computadores de mesa do escritório para, em momentos possíveis, entrar em chats de paquera e em site de pornografia. Não acho improvável que plataformas como join.me, google meet, hangout passem a ser utilizadas para um "date".

E, quando penso em 2017, isso é até engraçado ou mesmo seria tido como um passo muito grande e apresado após um match. Pois, há pouco tempo, convidar um crush para uma chamada de vídeo, tipo um Skype, era quase um pedido de casamento. Adiava-se esse tipo de contato que exige mais sincronicidade e enche a tela de informações que a gente não pode controlar completamente, tipo cenário, barulhos... exigindo uma interação menos customizada, entende? Por meio de texto e mesmo por voz, desde que a gente fique no assincrônico, temos mais como customizar a conversa: escolher melhor as palavras, os links, os emojis, as figurinhas, os memes...

Em uma matéria escrita por Thaís Monteiro, em junho de 2020, para o site Meio e Mensagem a gente viu que, cito literalmente, “[o] Happn notou um aumento de $18 \%$ nas mensagens trocadas pelo aplicativo; o The Inner Circle teve um aumento de $15 \%$ nos matches e 10\% nas mensagens enviadas; e o Par Perfeito registrou crescimento de $70 \%$ de novos usuários, um ganho de $20 \%$ no tempo médio gasto no aplicativo e site $15 \%$ de volume de mensagens trocadas desde o início de março”. E que muitas pessoas estavam fazendo o primeiro encontro por chamada de vídeo.

Os dados divulgados pelo Tinder e reforçados pelo Happn é que a conversa no app cresceu. Eu acho entranho, porque quando eu estava fazendo pesquisa, as pessoas chamavam logo para o WhatsApp. Ficar no chat do app, naquele momento, não era algo que apontava disposição para seguir conversando até, talvez, chamar para encontrar, mas era adiar a aproximação. Ou seja, novos tempos, novos usos da tecnologia. Talvez as pessoas estivessem, durante o isolamento, buscando ficar menos demandadas por outras mensagens que poderiam vir pelo WhatsApp, concentrando-se, assim, mais numa só conversa, via app. Bem, é apenas uma hipótese, levando em conta que as demandas de trabalho passaram a vir muito mais pelo Whats que por e-mails, nesse tempo de isolamento.

Para os apps de paquera, que são plataformas comerciais, é bacana que você fique em casa e acesse mais os meios digitais. Um "contatinho" do Happn vai aparecer como sugestão de amizade no Facebook, o mesmo no Tinder, em todos temos publicidades, todos trabalham com algoritimos que vão trazer para a tua tela anúncios associados aos teus desejos. Ou a desejos que você nem estava aspirando.

Os aplicativos de paquera, como o Tinder, chegaram a liberar funções que antes eram pagas como o "passaporte", possibilitar as/os usuárias/os a conversarem com pessoas que estão em outros países. Vamos dizer que conhecer gente é estimulante. Mas é também 
estressante, é exigente. Gente é exigente. Por isso eu acredito, veremos, que muitos amores digitais nascidos das quarentenas não vão se sustentar fora dela, porque ela mesma oferecia o cenário apropriado para aquela experiência de aproximação editada, customizada e regulada. Tipo "Amor em Tempos de Cólera”, do escritor colombiano Garcia Marques. Quando Fermina Daza, a protagonista, finalmente tem a chance de estar com Florentino Ariza, que, aliás era um telegrafo, tipo, trabalhava com comunicação e mensagens curtas, o achou sumamente desinteressante. Ele foi capaz de ser muito desejado por ela quando lhes mandava cartas e o clima era de interdição do romance dos dois. Quando se viam de longe e as conversas eram curtas e cortadas pela não aprovação de parte da família dela a flama da paixão foi alimentada. Isso era no final do século XIX e nós estamos na segunda década do século XXI, há mais de 180 dias DC, depois do Coronavirus, desde que a Organização Mundial da Saúde decretou que se tratava de uma pandemia e que, ao contrário de pandemias mais recentes, como a da aids, por exemplo, essa teve efeitos súbitos e inesperados, sobretudo os impactos econômicos, a acentuação das desigualdades (veja como o protocolo "fique em casa", toma como certo que todo mundo tem uma casa para ficar, que a casa é um lugar seguro, que há possibilidade de distanciamento dentro de casa, casa as diferentes populações que habitam esse mundo têm modelos de moradia nos moldes burgueses). Assistimos mais mortes, mas ainda são, em sua maioria, mortes de corpos que não importam, com muitas aspas, por favor. $O$ vírus saiu dos condomínios da Barra da Tijuca ou dos prédios sofisticados do Morumbi ou Boa Viagem ou de Meireles, para as periferias. Chegamos a cifras trágicas e inimagináveis em março de 2020.

Diferente de outras pandemias recentes, essa acontece quando as mídias digitais e seus suportes estão mais disseminados e acessíveis e isso também tem um efeito na forma como ela é apropriada pelas pessoas. E também como podemos vivê-la, uma vez que a interdição desta vez é de termos contatos físicos próximos com pessoas que já eram nossas conhecidas, aliás, mesmo com aquelas que são da família.

Como nesse momento em que os espaços físicos de paquera não estão completamente liberados, os encontros entre amigos e familiares podem ser perigosos e devem ser evitados, as pessoas passaram a buscar ainda mais recursos digitais para se sentirem próximas.

Já estamos vivendo muitos impactos do isolamento, sobretudo na economia, no lazer, na forma de ocupar os espaços, na forma até mesmo de protestar e fazer política, em dar aulas, mas ainda acho cedo para a gente dizer "ah isso veio para ficar"; "depois da pandemia o mundo viverá um momento de desbunde”; "a máscara será o novo pretinho básico"; "vamos olhar mais para as periferias”... esse tipo de futurismo me parece quando não ingênuo, preciptado.

Por outro lado, vamos sim assistir mudanças, mas algumas só serão mais sensíveis daqui a uns anos ou mesmo décadas. Por exemplo, levamos quase duas décadas para sentir impactos da aids no crescimento dos estudos de gênero e sexualidade... na própria formulação da teoria queer. 
MÁRIO FELLIPE: Em várias partes do livro, você aponta a pesquisa realizada em mídias digitais como sendo bastante exigente e até mais absorvente do que outras que você realizou anteriormente. O título da introdução do livro "Agitada pelas sensações, inicio", é bastante revelador nesse sentido. Quais as dificuldades que você acredita que um pesquisador que envereda por esse campo digital enfrenta?

LARISSA PELÚCIO: Ter a pesquisa no bolso é um deles. Está o tempo todo envolvido no cenário etnográfico, mas não ao modo Malinowisk, porque você não está em Trombriand, vendo da sua tenda a vida da aldeia se desenrolar frente aos seus olhos. Você tá na fila do supermercado; tá na sala de aula; na reunião do departamento; no sofá da sala vendo uma série domingo às duas da tarde... quer dizer, você está vivendo a sua vida cotidiana e a pesquisa te interpela o tempo todo. Por outro lado, essa é sua "tenda” móvel, pois essas interpelações, via notificações de mensagens no celular, era também o que os colaboradores da pesquisa viviam. Não tenho a intenção de fazer analogias entre uma forma de fazer etnografia nos moldes clássicos com o que se faz em meios digitais, mas é inegável que trazemos na bagagem os aprendizados metodológicos que já passaram por diversas críticas, revisões, redesenhos...

Quando se trabalha essencialmente on-line, não há aquele momento de ir a campo. Lembro-me, por exemplo, de minha pesquisa de doutorado, realizada em contextos urbanos, quando eu tinha uma agenda de deslocamentos, parte dela pautada pela própria dinâmica das e dos sujeitos da pesquisa. Nos meios digitais, os dados se acumulam de uma forma extraordinária. Tudo que você organizou e sistematizou ontem, ganhou novo volume hoje. É preciso segurar a ansiedade para não achar que se está fazendo um trabalho de Sísifo. Além disso, temos que considerar que quando se faz pesquisa já estando na docência em uma universidade pública, é preciso se envolver com ensino, extensão e gestão. Quero dizer, que temos que seguir com a pesquisa, o diário de campo, a sistematização de dados em meio a outras tantas demandas de trabalho.

Antes de falar da dimensão do afeto, quero dizer que para a pesquisa que eu estava realizando, diante das questões que eu me coloquei sobre "Como o capitalismo molda e transforma a vida emocional e a individualidade?"; "Como os homens estavam respondendo em suas vidas íntimas e cotidianas à inflexão feminista pela qual o país vinha passando”; "como o político se torna pessoal"... sentir essa pressão angustiante de nunca findar a sistematização dos dados; da falta de tempo e de fazer o diário de campo, da urgência de ter de responder a mensagens para não perder o colaborador, de ser acionada em momentos que eram para mim inapropriados, foram sensações e experiências de extrema importância etnográfica. Pois se eu tivesse um celular só para fazer a pesquisa, imagino que eu iria conectá-lo só em alguns momentos do dia e não iria ter a experiência que as pessoas realmente têm quando estão nos aplicativos de paquera. Então, viver tudo isso foi 
fundamental para eu ter aquela necessária aproximação com a alteridade, com as vivências digitais dos colaboradores da pesquisa.

E sobre afetos e desafetos, bem, é preciso levar muito a sério quais são seus limites como indivíduo para fazer uma pesquisa. É preciso considerar também em que momento da sua vida você está. Não dar conta de um determinado tema de pesquisa não te faz menos antropólogo ou menos socióloga ou psicólogo ou terapeuta ocupacional... talvez eu não desse conta de trabalhar com narrativas de abuso sexual, e ainda bem tem gente que dá e faz pesquisa superimportantes. Então, é preciso reconhecer esses limites e olhá-los de frente para que você não se frustre, não cometa deslizes éticos, não abandone a pesquisa financiada ou, mais grave, não cause problemas no campo e entre as pessoas que estão envolvidas no seu trabalho.

No meu caso, penso que se eu não tivesse solteira no momento dessa pesquisa tudo teria sido mais difícil. Não falo por conta de um suposto parceiro que poderia ter ciúmes, isso poderia bem acontecer, mas talvez porque eu mesma tivesse menos disposição de estar ali com tanta constância interagindo com homens interessantes e outros bem desinteressantes, falo do ponto de vista de meus desejos e de minhas afeições pessoais. Para a pesquisadora, todos eram interessantes.

MÁRIO FELLIPE: Você aponta na sua pesquisa que as relações em apps possui 3 peculiaridades: a conectividade perpétua, a portabilidade permanente e a sincronicidade. Como você acredita que essas características modificam nossas relações sociais? Você acha que o fato de estarmos usando mais esses aplicativos de conversa e de paquera, por exemplo, tornam nossas relações mais ansiosas?

LARISSA PELÚCIO: O que tornou a vida ansiosa não foram os aplicativos de paquera, é o que penso. A comunicação digital é que respondeu bem a um cenário amplo no qual o neoliberalismo se tornou mais que uma resposta a uma crise do capitalismo, mas uma filosofia individualista que estimula a meritocracia a partir da precarização das vidas pela fragilização das instituições políticas que deviam suportar nossa existência coletiva. Dessa forma, o neoliberalismo se tornou também um sistema cultural que constitui subjetividades específicas.

Por outro lado, os aplicativos sendo utilizados a partir dessa lógica, alimentam um ansioso fluxo de conversas e demandas. Inclusive demandas por eficiência pessoal, seja na forma de estabelecer a comunicação ou de se apresentar iconograficamente. Quando em 2014, o WhatsApp trouxe a novidade dos sinais azuis de check associado à visualização da mensagem, não tinha em mente criar ansiedade nos usuários. O critério era a eficácia, mas a urgência com que passamos a lidar com a comunicação remota trouxe muitos desgastes provocados pelos risquinhos azuis ${ }^{5}$.

\footnotetext{
${ }^{5}$ Sinal gráfico que indica que a mensagem foi lida por quem a recebeu
} 
Vamos pensar nos pontos que você listou: a conectividade permanente é uma opção não uma imposição. Por que escolhemos não nos desconectar? Como essa ideia de estar sempre a par de tudo, de não perder nada, supondo-se que há mesmo algo a se perder, está associada a constituição de um modelo de sociedade que fincou seus pilares na competitividade, no individualismo extremo, no enxugamento do Estado e no enaltecimento do mercado. Passamos a ser indivíduos que se auto periciam, acreditamos e servimos à sociedade disciplinar foucaultiana e à sociedade de controle deleuziana ao mesmo tempo.

Veja que essa história da conectividade permanente não nasceu no seio dos afetos familiares ou de parcerias sexuais e amorosas, mas entre executivos. O Blackbarry, que surge no mercado em 2002, aparece como o primeiro protótipo dos smartphones, vinculado ao mundo corporativo, a empresa passou a estar no bolso do executivo e ainda foi se associando a um estilo de masculinidade bem-sucedido. O homem gerente de si, que otimizava o tempo do trabalho enquanto estava em ambientes fora da empresa. Aquele cara que em meados dos anos 90 erotizava o escritório vendo pornografia ou entrando em chats para paquera ali do computador de mesa do trabalho, agora está logado à empresa até quando está no banheiro. Não deve haver "tempo morto", só "tempo produtivo".

A portabilidade, inegavelmente, agrega muitos benefícios, mas traz consigo uma carga considerável de urgência de coisas que, de fato, podiam, até há bem pouco tempo, serem adiadas e até mesmo evitadas. Inclusive, nos poupando de gerar mais ansiedade e problemas ao nos precipitarmos a darmos uma resposta "just in time". Por que precisamos consultar, olhar, ler, responder de imediato? Porque no neoliberalismo com a urgência, que se confunde com eficiência. Nas palavras de Deleuze, "Nas sociedades de disciplina não se parava de recomeçar, enquanto nas sociedades de controle nunca se termina nada” (Deleuze, 1990, $\mathrm{s} / \mathrm{p})$.

MÁRIO FELLIPE: Sabemos que os apps são simultaneamente espaços midiáticos e comerciais. Sem desconsiderar as múltiplas formas de agência que os usuários mobilizam nesses espaços, que efeitos a incorporação de uma lógica mercadológica traz para as relações sociais? Você acha que assim como seus interlocutores estamos nos tornando investidores emocionais?

LARISSA PELÚCIO: Os colaboradores da pesquisa são pessoas como nós. Veja que até nosso vocabulário para falar de paquera mudou: acumulamos crush e matchs, investimentos, otimizamos, descartamos, nos comoditizamos em perfis que procuram anunciar o que acreditamos ser o melhor de nós mesmos... E o fazemos em nome do que? Por quê? O que significa cada like em sua timeline, em sua vida? Por que os likes importam? Aliás, a quem eles importam? Como as grandes empresas que dominam o mercado digital hoje (Google, Amazon, Facebook, Microsoft), nós também temos operado com a dataficação, mercantilização e seleção algorítmica de nossos afetos, de nossa vida privada. 
Jose Van Djick, pesquisadora holandesa, associa essa economia política dos likes à "plataformização da sociedade", quer dizer, o reconhecimento de que há uma "inextricável relação entre plataformas online e estruturas societais” (cf. DIGLABOUR 2020). Em outra entrevista, esta concedida às jornalistas e acadêmicas Isadora Camargo e Carolina Terra, Van Dijck observa que "o botão "curtir" revela reações instantâneas e emocionais, e é um mecanismo muito sofisticado que faz com que haja muito mais que uma "sensação boa de aprovação" (2017: p.173).

Temos dado um status de sucesso até de nosso fracasso (e aqui fracasso tem muitas aspas). Se gerar likes, pronto, temos o "sucesso". Essa estratégia de "vender" o que não deu certo é algo que o capitalismo sempre fez muito bem e que nossas subjetividades neoliberais captaram de forma eficiente, como convém ao sistema. Quer dizer, estamos capturadas e capturados por esse modelo que tornou a felicidade um imperativo individualizado e individualizante que pode ser mensurado digitalmente.

MÁRIO FELLIPE: Quando você fala que esse apps fomentam uma incitação constante nos usuários, expressa em um espírito de competição permanente que envolve a prática de uma sexualidade em série resultando no desprendimento emocional, o que esse conjunto de características se aproxima do que Bauman chamou de liquidez das relações sociais?

LARISSA PELÚCIO: Na verdade, não acho que haja um desprendimento emocional, há muita emoção em jogo, é preciso que seja emocionante para ser digno de ser vivido. As pessoas estão em busca de vidas mais emocionantes e chegam a acreditar que ter mais parceiras ou parceiros, no caso dos homens, ou ter um parceiro ou uma parceira, no caso de mulheres, que possam obter o passaporte para a felicidade. Mas a contradição está na sensação de que, ao encontrarmos alguém, estaríamos deixando de viver outras experiências que poderiam ser ainda melhores. Sabe aquela sensação de que você poderia estar vivendo uma vida melhor que essa sua aí? E que isso pode estar aí, a um like de distância, pode estar no próximo perfil... isso nos faz eternas buscadoras e buscadores. Daí é que vem a falta de engajamento, de não compromisso, um pavor juvenil do compromisso, do pacto, do refletir sobre sentimentos.

Vamos a Bauman. Eu acho que a liquidez não é uma boa metáfora para a gente falar dos amores em tempos de aplicativos. $\mathrm{Na}$ verdade, o estado líquido é tão bacana, tão moldável, tão fresco... tem fluxo, não é? Se for para seguirmos com os estados da água como metáfora eu escolheria o gasoso, porque ele pode turvar a visão, a gente não pode agarrar, tocar. Mas, seriamente, saindo das metáforas e indo ao Bauman. O que o sociólogo polonês foi capaz de apontar de forma direta e sem rodeios foi o paradoxo do presente implicado na formação do par. O par, essa utopia contemporânea, como classificou Eva Illouz, que tem de ser formado sob a égide do individualismo crescente, do consumismo terapêutico, quero dizer, como forma de estancar sofrimentos; esse par que precisa conciliar relações significativas com o descompromisso. Que tem de se manter feliz, produzindo felicidade 
para afastar o tédio, esse sim, supostamente, um vilão do romance... Como conciliar a busca por excitação permanente com as exigências de uma vida que requer rotina, certo planejamento, dia de faxina e moletom velho? Se eu não me comprometo com você, e não estou falando de fidelidade, de assinar uma certidão de casamento, falo em comprometerme com o seu sentimento, como posso viver uma relação significativa? Se comprometer com o sentimento do outro não é se atar ao desejo do outro. Sabe que isso angustiava muito colaboradores que eu tive em outra pesquisa (cf. PELUCIO 2015), do Ashley Madison? Era justamente a dificuldade de viver essa incitação à aventura, que passava pelo sexo erótico e não o sexo protocolar, e ao mesmo tempo fruir o gozo que só a intimidade dá. Olha, a intimidade não significa viver anos com a pessoa, mas ter uma vida compartilhada que é capaz de manter laços pelas afinidades intelectuais, políticas, morais e sexuais. É transar com alguém e não querer que a pessoa vire uma pizza depois da transa. Mas como ter intimidade quando a gente se tornar acumuladores de matchs? Quando estamos incitadas e a buscar sempre a aventura, o risco, o melhor perfil?

Bauman vai apontar esse paradoxo logo no prefácio do "Amor Líquido", quando ele fala no conflito entre apertar os laços e mantê-los, ao mesmo tempo, soltos. Ou, como diria meu pai, que nasceu 17 anos depois do Bauman: como fazer omeletes sem quebrar os ovos? É interessante como se leu Bauman quase como livro de autoajuda. Ele foi liquefeito nesse processo. É injusto até, pois o próprio Bauman critica teorias que são, de fato, reiterações de visões do senso comum.

Bauman foi um homem do seu tempo, brilhante, mas marcado por guerras, inclusive a guerra fria, forjado no marxismo, marcado pelo judaísmo. Em suma, muitas dessas marcas estão na escrita do seu "Amor Líquido". Por exemplo a oposição entre amor e desejo, ou a crença que os meios digitais eram os principais vilões, do que ele chamou de relacionamentos de bolso (vamos lembrar que Bauman tinha 75 anos quando publicou "Modernidade Líquida") ou a ideia mesmo de liquidez quando no campo dos relacionamentos, da pedagogia emocional, temos mais solidez ou cristalizações que liquidez, como é o caso das assimetrias de gênero.

Em suma, gosto muito do que o Bauman traz e gosto de colocá-lo em diálogo com outras autoras e autores, como Eva Illouz, e eu estou pensando em muitas contribuições dessa socióloga franco-marroquina, mas eu destacaria o "Por que o Amor dói", ainda não traduzido por português, e "Happycrasia".

MÁRIO FELLIPE: Explica para nós um pouco melhor o que seria essa nova economia do desejo que você fala no livro.

LARISSA PELÚCIO: A expressão aparece em 2010 cunhada pela socióloga norte-americana Elisabeth Bernestein (cf. "Temporarily Yours: intimacy, authenticity, and the commerce of sex"), pensando em mercado do sexo, novas configurações das cidades da costa oeste norteamericana, mudanças na forma da classe média profissional ocupar esses espaços, além das 
transformações no mundo do trabalho e do consumo, super ligadas às transformações digitais. Foi o Richard Miskolci que me apresentou esse texto e ele mesmo trabalhou com esse conceito num artigo chamado São Francisco e a nova economia do desejo, que saiu em 2014, na Lua Nova. Ele vai desenvolver mais essa ideia conectada aos relacionamentos mediados pelos aplicativos no livro dele, o "Desejos Digitais".

Ele escreve, analisando o campo etnográfico dele, entre homens que buscavam sexo com homens por meio de aplicativos. Para o Richard, e eu concordo com ele, sem a gente emprestar um olhar macrossocial para ler as intimidades, a gente deixaria escapar muitos elementos fundamentais para entender o sucesso dos aplicativos.

Procurar intimidade por esses meios parece, então, um paradoxo. A própria (mercado)lógica dos aplicativos, baseados na mecânica do descarte e da economia afetiva da abundância, incita à busca eterna. Essa nova economia do desejo está fortemente informada por esferas da vida que parecem apartadas e mesmo antagônicas, mas as tomo como fortemente relacionadas: a produção subjetiva do desejo no campo dos afetos e as dinâmicas contemporâneas do mercado.

Essa nova economia do desejo está fortemente informada por esferas da vida que parecem apartadas e mesmo antagônicas, mas eu as tomo como fortemente relacionadas: a produção subjetiva do desejo no campo dos afetos e as dinâmicas contemporâneas do mercado.

A associação entre consumo, sexo e amor vem se combinando em uma "economia política do romance” (ILLOUZ 2009: p.115). Otimizar, investir, não perder tempo nem dinheiro, negociar, consumir lugares... Um empreendedorismo emocional que tem gerado todo um mercado de "ajuda" mútua na internet com cursos sobre sedução on-line que ensinam como compor um perfil de "sucesso", encetar as melhores conversas por WhatsApp e em que aplicativos investir tempo, dinheiro e desprender toda uma energia emocional.

Eu gosto da proposta da Eva Illouz em trabalhar com o conceito de Capitalismo afetivo. Ser um bom gestor das emoções lhe confere um capital importante no mercado dos afetos. Para Illouz, os sentimentos são personagens centrais na história do capitalismo. Vejam que nada mais cool que uma empresa, na qual você tem ambientes que supostamente promoveriam a criatividade, proporcionariam a distensão do formalismo do mundo do trabalho criando cenários descontraídos, incentivando a gestão pessoal do tempo, a partir da ideia mobilizadora das "metas", nos quais os termos em inglês são tão comuns quanto as barbas bem desenhadas e coques samurais. Porém, não se tem férias remuneradas, nem décimo terceiro, onde a pessoa é colaboradora, quer dizer... tem sua situação de trabalho precarizada. O neoliberalismo foi capaz de transformar palavras tão legais como flexibilidade, colaborador, empreender, em termos que falam, na verdade, de relações desiguais e violentas.

Sem regulações claras, estão todos um tanto tateantes diante desse novo regime de gestão dos sentimentos. A flexibilidade emocional reproduz algumas das características do 
termo aplicado ao mundo do trabalho, com contratos fluídos e informalização das pactuações que regiam as relações entre as partes.

A flexibilização carrega muitas incertezas e umas tantas inseguranças. O que a Illouz chama de competência afetiva é, na leitura incrível que ela faz dessa vigilância emocional, que a gente tem de se submeter em certos ambientes hostis, seja de trabalho ou de sociabilidade, a um recurso altamente individualizado e psicologizado de sermos responsabilizadas por gerir emoções.

E de como isso passa a ser capitalizado por empresas, por exemplo. Pensem nas pessoas que fazem telemarketing ou que estão nos calls centers, como precisam desenvolver essa competência sem qualquer suporte emocional que não a punição se falharem. Nos aplicativos, eu senti isso muitas vezes. Como pesquisadora, eu tinha que gerenciar minhas emoções diante de investidas agressivas ou, ao contrário, de homens que confundiam o que eu estava fazendo ali e partiam para o flerte; outros que precisavam desabafar, e como vocês sabem, não tenho formação em psicologia, e era preciso desenvolver habilidades emocionais para lidar com toda essa carga de relatos e abordagens.

Os homens que colaboraram na pesquisa também tiveram de aprender a desenvolver essas habilidades, nem todos foram bem-sucedidos.

Apareceram queixa também entre os colaboradores da pesquisa. Saber "chegar" na mulher, mostrar-se interessado em algo mais que sexo, quando se quer mesmo só sexo; mas um sexo bom, sem compromisso, mas com intimidade... Lidar bem quando se é bloqueado, abandonado, trocado... quando não se recebe respostas depois de um macth ou um crush.

O mercado dos afetos é regido por um suposto poder radical de escolha do usuário, algo "empoderador" e que atrai fortemente para o uso dessas plataformas, já que a experiência emocional da grande maioria das pessoas no mercado afetivo (antigo e mesmo atual) é a de não ter controle e ser mais preterido do que escolhido.

MÁRIO FELLIPE: Em uma paisagem emocional marcada por uma hipervisibilidade do eu, por relações cada vez mais aceleradas e individualizadas, onde o outro parece cumprir uma função meramente acessória no laço social, como você acha que a busca constante por experiências estimulantes, personificadas no casal feliz que não se entedia na companhia do outro, tem nos infantilizado e nos feito perder certo senso de realidade?

LARISSA PELÚCIO: Acho que essa é nossa realidade. Não estamos fugindo dela, mas com certeza estamos com dificuldades de lidar com um mundo que nós mesmo ajudamos a construir. Esse ceticismo emocional apareceu muito nas conversas que eu tive com os meus mais de 300 crush e matchs. E, nas minha análises, dialogando com muitas teóricas e teóricos, o que eu percebia é que há uma impossibilidade de se conciliar dois modelos de relacionamentos e de subjetividades históricas: o amor romântico do final do século XIX até meados do século XX e o amor contemporâneo, as subjetividades da era industrial e do neoliberalismo tecnológico. Um fala de fidelidade, de assimetria de gênero, de relações 
longevas, heterossexuais, de um encontro sexual cálido e retumbante, ao mesmo tempo, o outro incita o experimentalismo, a aventura, o acúmulo, o gozo seriado e nunca satisfeito. E aqui eu concordo com o Bauman, que o desejo azeita o sistema que precisa que nunca estejamos saciadas ou saciados.

É muito doido isso, e não tem como dar certo. Nós crescemos sendo estimuladas a acreditar nos benefícios do amor romântico. Há, pelo menos 100 anos, tivemos o match entre o amor e o mercado. Ser feliz a dois é poder viver em excitante consumo de emoções, jantares, presentes, viagens, administrando bem o tempo, otimizando os encontros, contabilizando as conquistas materiais e acumulando experiências. Se a vida fosse uma comédia romântica ou um anúncio de cartão de crédito talvez esse roteiro funcionasse.

Adriana García-Andrade e Olga Sabido-Gomes mostram que a semântica do amor romântico pressupõe certas condições materiais e culturais para fazer sentido. Mas, para além dessas condições que serão específicas em suas marcas históricas, sociais e econômicas, é preciso considerar que viemos operando com uma linguagem na qual a assimetria de gênero tem sido uma espécie de termo flutuante capaz de organizar as relações amorosas/sexuais, assegurando certa previsibilidade frente às expectativas de como deve ser uma mulher e de como deve se comportar um homem quando o tema é romance.

As mesmas autoras reconhecem que essa semântica teve, no presente, que lidar com mudanças sintáticas, na estrutura mesmo do amor romântico pensado historicamente como exclusivamente heterossexual e assentado na dominação masculina. O que me mobilizou quando iniciei esta pesquisa foi o paradoxo entre emancipação das mulheres, politização dos temas associados a gênero e sexualidade acompanhados por relatos de meus interlocutores manifestando dificuldades de desenvolverem relações satisfatórias com mulheres cujo perfil socio-cultural os atraia e desafiava a um só tempo.

Paralelo a essas narrativas, cada vez mais escutava em retalhos de conversas que ouvimos em espaços públicos, confissões de amigas, desabafos de alunas, queixas sobre as dificuldades de estabelecerem relações heterossexuais satisfatórias, justamente por serem assimétricas em termos afetivos mesmo quando pautadas em trocas mais equilibradas em termos simbólicos e materiais.

MÁRIO FELIPE: As empresas têm se apropriado de nossa sagacidade em nos apresentarmos nas mídias de forma natural, de modo que nos pareçamos espontâneos e desinteressados, performando aquilo que o fundador do Facebook cunhou de "Amigo confiável". A própria vida só passa a existir como tal, só se converte em minha vida quando ela assume um caráter narrativo e é narrada na primeira pessoa do singular, conforme afirma Paula Sibília no livro "O Show do Eu: a intimidade como espetáculo". Na sua opinião, quais são os efeitos de um movimento de curadoria do eu nas redes sociais onde a intimidade do indivíduo vem se tornado cada vez mais pública (uma extimidade) e onde o nosso reconhecimento social encontra-se diretamente vinculado com nossa capacidade de performar naturalidade nesses espaços? 
LARISSA PELÚCIO: É interessante que a gente esteja emprestando termos do mercado e do mundo do trabalho para falar de amor e afetos. Quando um homem faz isso ele masculiniza o campo das emoções, associado, no senso comum, às mulheres. Por outro lado, acho que recorrer a esse vocabulário sinaliza que talvez a gente ainda não tenha encontrado termos capazes de nos oferecer um campo semântico no qual a gente possa organizar essas experiências. O que acho que nos infantiliza emocionalmente é usar as ferramentas da tecnologia para nos desincumbir de lidar com as relações que construímos e com as nossas próprias emoções.

Os aplicativos móveis para fins de relacionamentos amorosos/sexuais integram um complexo campo no qual a dinâmica da vida contemporânea é pautada pela aceleração do tempo, maior exigência no campo do trabalho e a sua flagrante precarização. Some-se a esse cenário um conjunto de ansiedades que entrelaça esfera pública e privada, tais como o aumento da violência urbana, as urgências emocionais relativas aos anseios estimulados por diversos discursos que nos convocam a sermos felizes, saudáveis, aventureiros/as. Conformando as já muito discutidas transformações na esfera íntima da família e do amor romântico (GIDDENS1993; BAUMAN 2004; ILLOUZ 2009) essas demandas coadunam-se com as possibilidades emocionais ofertadas pelas novas tecnologias, pactuando uma estreita relação entre estas e os sentimentos.

As tecnologias digitais são densamente emocionais. Imagens, voz, escrita inserem as pessoas em circuitos subjetivos labirínticos, permeados não só por expectativas e alegrias, mas sobretudo por temores, incertezas, dores e frustração. Mercado dos afetos é um jogo em que a maioria sai perdendo, posto que a regra básica do mercado é a desigualdade de acesso aos bens disputados

MÁRIO FELLIPE: Cada vez mais privatização individual e cada vez menos refúgio na interioridade. Você acha que essa tendência contemporânea e uma perda da dimensão do outro no nosso horizonte tem tornado a quarentena mais difícil?

LARISSA PELÚCIO: Não sei se entendi tua pergunta. No meio de uma pandemia, temos um cenário tão violento!! Olha o número de pessoas mortas, não pelo vírus, mas por balas de policiais. Sabemos que são corpos negros. Isso não está passando batido. A sensação de que estamos sendo furtados de vida é algo que a classe média experimenta, mas as vidas periféricas são furtadas há séculos e diariamente. O que tornou o isolamento social difícil para a classe média foi justamente ter de lidar com a dor do outro diariamente, fosse pelas mídias digitais, pelos conteúdos noticiosos, seja porque a faxineira não podia estar ali para limpar a casa ou porque os filhos não estavam indo para a escola, porque tinha de cuidar de um familiar doente. 
MÁRIO FELLIPE: Em um contexto de profundas inflexões na vida brasileira que tiveram seu início com a revolução sexual dos anos 1960 e se aprofundaram com a discussão sobre os feminismos, sobre o racismo e sobre uma vida social mais inclusiva, onde você acha que nos perdemos no caminho ao ver hoje, no Brasil, um aumento do conservadorismo e de posturas fascistas e anti-intelectualistas que despotencializam em, alguma medida, os esforços construídos, em parte, pelos movimentos sociais, pelas esquerdas e pela universidade em viabilizar um mundo mais justo e menos desigual? Será que erramos ao falar difícil demais sobre as diferentes pessoas em situação de vulnerabilidade que pretendemos atingir com nossos estudos? Por que você acha que uma parcela da população se identifica com a figura de Bolsonaro a despeito de todos os absurdos que diariamente ele profere?

LARISSA PELÚCIO: A gente tem já muita produção sobre por que Bolsonaro teve os votos que teve. Assim como temos pesquisas mais recentes que mostram que há cerca de $30 \%$ de pessoas que se mantém fiéis ao seu voto e que cerca de $12 \%$ são bolsonaristas incondicionais. Bolsonaro foi eleito pela campanha antipetista orquestrada, inclusive pelos antibolsonaritas de última hora como o conglomerado Globo. Sabemos também que o voto em Bolsonaro foi um voto revanchista, contrário às políticas igualitárias e de promoção de direitos às minorias políticas. As estatísticas mostraram claramente o perfil do eleitorado bolsonarista naquele momento das eleições. Já temos mudanças. Mas quero que a gente foque nesse perfil de gente de classe média profissional, de homens brancos e relativamente jovens.

A perseguição anti-intelectual desse governo, no meu entendimento, mostra claramente, que o que estamos fazendo nas universidades faz e fez diferença. Essa diferença também ecou dentro dos campos universitários. Tivemos eventos incríveis, com debates potentes, mas também tivemos muitas animosidades dentro desses espaços. Quem aqui nunca foi atacada num post no Facebook, não por bolsonaristas, estou falando de um momento no qual Bolsonaro não era mais que um meme? Muita gente adotou linguagem violenta, acionou lugar de cala, confundindo o lugar de fala com uma ação autoritária e sim, isso dói, e é anti-intelectual sim. A gente tem problemas sim de comunicação, de linguagem... mas veja, muito do vocabulário que hoje circula em movimentos sociais diversos foram forjados no campo engajado de pesquisas acadêmicas. Mas quero convidar a gente a pensar como contribuímos para o Bolsonaro ser eleito? Esse não é um convite que se adere facilmente, mas temos que fazer esse exercício urgentemente. Se não reaprendermos a dialogar, se ficarmos só cancelando, bloqueando e descartando pessoas e opiniões, não iremos construir democracia. A democracia é trabalhosa, exigente e toma tempo. Silenciar pessoas é autoritário. A realidade e pesquisas acadêmicas e de opinião mostram que as redes sociais digitais não são nem o único e muito menos o melhor lugar para se fazer política, o que implica em dialogar, olhar no olho, ouvir o outro até o fim de seu argumento, e não silenciá-lo, "discutir-lo", sem ao menos ver o "leia mais". 
Nosso match com um Brasil mais plural, mais cidadão, menos violento fracassou. Mas isso não nos autoriza a desistir de (re)construir uma agenda de luta mais prismática e menos rancorosa. E isso, temos que fazer também e, sobretudo, nas ruas e não nas redes. Hashtag chega de cancelamentos, hashtag bora dialogar, hashtag mais alianças e menos vinganças. Eu quero um match com um Brasil libertário.

\section{Referências Bibliográficas}

BAUMAN, Zigmunt. (2004). Amor Líquido: sobre a fragilidade dos laços humanos. Trad. Carlos Alberto Medeiros. Rio de Janeiro: Zahar.

BERNSTEIN, Elizabeth. (2007) Temporarily Yours: intimacy, authenticity, and the commerce of sex. Chicano: The University of Chicago Press.

CABANAS, Edgar, ILLOUZ, Eva. (2019). Happycracia Cómo la ciencia y la industria de la felicidad controlan nuestras vidas. Madrid. Paidós.

CAMARGO, Isadora; TERRA, Carolina. (2017). Faces da conectividade: Plataformas, Influência e Usuários. Parágrafo.v. 5, n.1., s/p.

DIGLABOUR. (2019). A Sociedade da Plataforma: entrevista com José van Dijck. 6/03/2019. Disponível em https://digilabour.com.br/2019/03/06/a-sociedade-daplataforma-entrevista-com-jose-van-dijck/ acesso em 27/09/2020

DELEUZE, Gilles. Post-scriptum sobre as sociedades de controle. In: Conversações: 19721990. Rio de Janeiro: Ed. 34, 1992, p. 219-226. Tradução de Peter Pál Pelbart.

FRANCO, César B. (2015). “Como Conquistar Mulheres?” - Masculinidade e Subjetivação em uma Comunidade Virtual. Dissertação de Mestrado em Sociologia. Curitiba: Universidade Federal do Paraná.

GARCÍA MÁRQUEZ, Gabriel. El amor en los tiempos del cólera. 18 ed. Buenos Aires: Debolsillo, 2011.

GARCÍA-ANDRADE, Adriana; SABIDO-RAMOS, Olga. (2018). The invisible ties we share: a relational analysis of the contemporary loving couple. Feminism and the power of love. Interdisciplinary Interventions. Routledge: London.

GIDDENS, Anthony. (1993). Transformações da intimidade: sexualidade, amor e erotismo nas sociedades modernas. São Paulo: Ed. UNESP.

ILLOUZ, Eva. (2012). ¿Por qué duele el amor? Una explicación sociológica. Traducción de María Victoria Rodil. Buenos Aires: Katz.

ILlOUZ, Eva. (2013). “Don't Be My Valentine: Are Couples Becoming a Thing of the Past"? Haaretz, Israel. Disponível em: www.haaretz.com/israel-news/don-t-be-my-valentineare-couples-becoming-a-thing-of-the-past.premium-1.503597. Acesso em 19/09/2020.

ILLOUZ, Eva. (2009). El consumo de la utopía romántica. El amor y las contradicciones culturales del capitalismo. Katz Editores: Madrid. 2009.

MISKOLCI, Richard. (2014). San Francisco e a nova economia do desejo. Lua Nova: Revista de Cultura e Política, 2014, 91: 269-295. 
PELÚCIO, Larissa. (2015). Narrativas infiéis: notas metodológicas e afetivas sobre experiências das masculinidades em um site de encontros para pessoas casadas. Cadernos Pagu, n. 44, p. 31-60.

PELÚCIO, Larissa. (2020). Um match com os conservadorismos: masculinidades desafiadas nas relações heterossexuais por meios digitais. Interfaces Científicas, vol.8. n.2. p.31-46.

PELÚCIO, Larissa (2019). Amor em Tempos de Aplicativo: Masculinidades Heterossexuais e a nova economia do desejo. 1. ed. São Paulo: Annablume.

SIBILIA, Paula. (2008). O show do Eu: a intimidade como espetáculo. Rio de Janeiro: Nova Fronteira.

Recebido em 29/09/2020

Aceito para publicação em 14/01/2020 